\title{
Study of radiological outcome of total hip arthroplasty in displaced neck of femur fracture
}

\author{
R. Sahaya Jose
}

Assistant Professor, Dept. of Orthopaedics, Sree Mookambika Institute of Medical Sciences, Dr. MGR Medical University, Tamil Nadu, India

\section{*Corresponding Author: R. Sahaya Jose}

Email: drjose07@yahoo.co.in

\begin{abstract}
Introduction and Objectives: The Purpose of this study is to assess the Radiological outcome of Total Hip Arthroplasty in Displaced fracture Neck of femur.

Materials and Methods: 22 patients of displaced intracapsular neck of femur fracture were included in this study of which 14 patients managed through cemented and 8 managed through Uncemented Total Hip Arthroplasty, respectively. In this study patients operated with uncemented implants were assessed for radiological outcome by utilizing Andrew Whaley and Daniel et al and Engh's criteria while patients operated with cemented implants were assessed for radiological outcome by utilizing De Lee and Charnley criteria and Gruen Zone Criteria. The Data was analyzed by SPSS 20.00 using Chi-square test.

Results: In our study period no loosening of acetabular or femoral components were noticed. Acetabular cup inclination was normal in $77 \%$, vertical in $14 \%$ and horizontal in $9 \%$. Position of the stem of femoral component was neutral in $73 \%$ with $13.5 \%$ of varus and valgus each. No vertical subsidence and no migration of acetabular cup was seen in our study. There was $4.5 \%$ i.e., one patient developed Type II Heterotopic ossification.

Conclusion: The results of this study shows that Total Hip Arthroplasty gave better results in Displaced Intracapsular Neck of femur fractures radiologically. Also there was no loosening of Acetabular component or migration of acetabular cup and cup position was normal in $77 \%$ cases. Femoral stem position was Neutral in $73 \%$ of cases with no vertical subsidence and no femoral component loosening.
\end{abstract}

Keywords: Total hip arthroplasty, Radiological outcome, Neck of femur fracture.

\section{Introduction}

The treatment of displaced Neck of Femur fracture in elderly patients is highly controversial. In Hemiarthroplasty there is more chance of Non-union and high rate of bone wear leading to revision surgery. Therefore nowadays Total Hip Arthroplasty (THA) is primarily done to prevent such complications. The goal of THA is to provide full functional state for the patient as swiftly as possible. THA is a challenging surgery done for displaced fracture neck of femur which has good functional as well as radiological outcome. The outcome of THA is usually assessed functionally as well as radiologically. Radiological assessment is equally important for the long term survival of the THA prosthesis.

In our study we have decided to evaluate the radiological outcome of both cemented and un-cemented THA. We used Posterior approach in all the cases of THA and we used the second generation cementing techniques for cemented THA. Radiographic evaluation includes Loosening of the acetabulum and femoral components, Inclination of Acetabular cup, Stem position of femoral component, Vertical subsidence, Migration of the Acetabular cup and Heterotopic Ossification.

Based on Andrew Whaley and Daniel et al criteria(JBJS 83A 2001) ${ }^{1}$ radiological assessment of acetabular components in uncemented acetabulum is done and defined loosening when Migration of $>2 \mathrm{~mm}$ in horizontal /vertical direction, Rotation of implant, Screw breakage or more than $1 \mathrm{~mm}$ radiolucent line in all zones. Loosening in cemented acetabular components is assessed in 3 zones defined by De Lee and Charnley criteria (Clin Orth op, 121,174) ${ }^{2}$ which manifest as radiolucent line between cement-bone and cement-cup interface, distribution, thickness and progression of these lines, tilting and bulk migration of the socket in relation to the bone in X-rays.

Similarly radiological evaluation of cemented femoral component was done by Gruen Zone Criteria ${ }^{2}$ (Clinic Orthop, 1979) and assessed for fractured acrylic cement, interface gap between stem-cement and cement-bone interface of more than $2 \mathrm{~mm}$ in width, gross movement of femoral component and stem fracture. Uncemented femoral component was assessed by Engh's criteria ${ }^{3}$ (Clinic Orthop 1990-257) and evaluated as stable bone growth or fibrous fixation or unstable.

Acetabular cup inclination ${ }^{4}$ was measured by AP radiograph by 2 lines, one is trans-ischial line and other line parallel to opening of acetabuar component, and grouped in to Normal $\left(30-40^{\circ}\right)$, Vertical $\left(>45^{\circ}\right)$ and Horizontal $\operatorname{cup}\left(<30^{\circ}\right)$ alignment. Femoral stem position ${ }^{4}$ is determined as Varus, Valgus or Centre based on angle made by the lines drawn from mid points of transverse diameter of shaft of femur and the stem of the femoral component at $1 \mathrm{~cm}, 3 \mathrm{~cm}$ and $5 \mathrm{~cm}$ from the tip of femoral stem.

Vertical subsidence of the femoral component was measured by determination of the change in the distance from the superomedial extent of the porous coating to the most proximal point on the lesser trochanter. A decrease of $5 \mathrm{~mm}$ or more in the vertical position was considered to indicate subsidence.

Vertical migration of the acetabular component was determined by measurement of the change in the vertical distance from a transverse line drawn through the inferior aspect of both tear drops to a transverse line drawn through the center of the spherical acetabular cup. 
Heterotopic ossification was graded according to the Brooker et al. ${ }^{5}$ classification in to Grade I-IV, with Grade IV being Ankylosis.

Observations and measurements were evaluated using the X-ray AP view of the pelvis and X-ray AP/lateral view of the operated hip during post op, 6 weeks and then 6 months once follow up.

\section{Materials and Methods}

Study Area: Sree Mookambika Institute of Medical Sciences

Both retrospective and prospective study (2011-2017)

\section{Inclusion Criteria}

1. Displaced Intracapsular Neck of Femur Fracture

2. Patients 60 years of age and above

3. Non-union Neck of Femur

\section{Exclusion Criteria}

1. Young patients

2. Pathological femur fractures.

3. Associated with other Lower limb fractures

4. Patients with neuromuscular disorders

5. Infections

$\begin{array}{lll}\text { No. of patients } & - & 22 \\ \text { Total No. of hips } & - & 22 \\ \text { Age } & - & \text { Above } 60 \text { years } \\ \text { Cemented: Uncemented } & - & 14: 8 \\ \text { Right: Left } & - & 11: 11 \\ \text { Approach } & - & \text { Posterior } \\ \text { Unilateral: Bilateral } & - & 22: 0 \\ \text { Study } & - & \text { Retrospective and } \\ & & \text { Prospective } \\ \text { Follow up } & - & 12 \text { months }-84 \text { months } \\ \text { (Mean follow up }-31.9 \text { months) } & \end{array}$

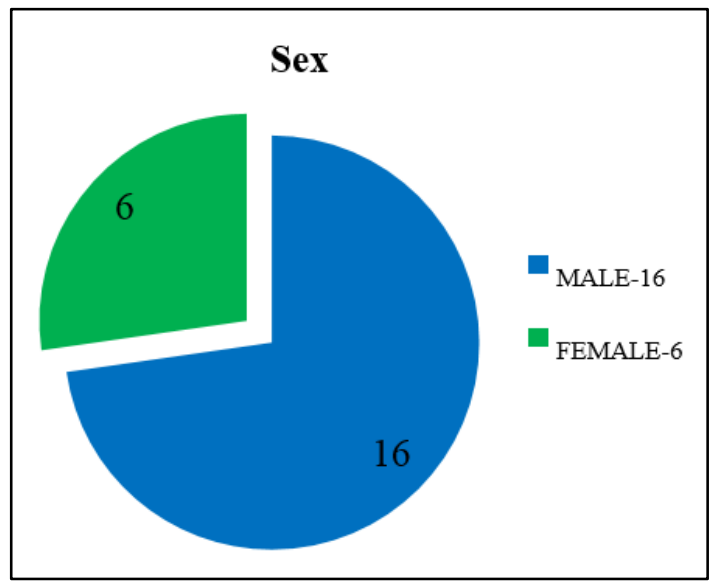

Fig. 1

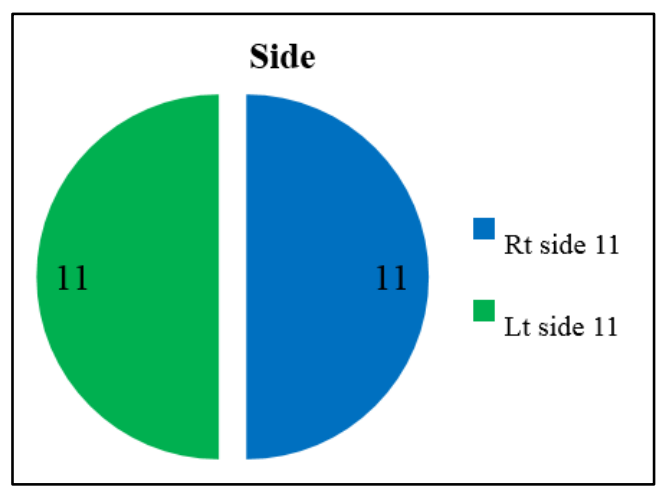

Fig. 2



Fig. 3

\section{Follow Up}

1. Prospective patients were reviewed regularly and at 6 weeks, 3 months, 6 months, 1 year and then yearly follow up.

2. Retrospective study patients were reviewed every yearly.

3. Patients were assessed radiologically using $\mathrm{X}$ ray Antero-posterior view of Pelvis with both Hips and Antero-posterior and Lateral view of operated Hip.

\section{Results}

Observations and measurements were done on the AP radiograph of pelvis and AP/Lateral view of operated hip. Radiographic evaluation included.

1. Loosening of the acetabulum and femoral components.

2. Acetabular cup inclination

3. Femoral stem position

4. Vertical subsidence

5. Migration of Acetabular cup

6. Heterotopic Ossification

\section{Loosening of the Acetabular components and femoral components}

There was nil acetabular and femoral loosening.

\section{Acetabular Cup inclination}

Cup inclination is an important component of radiological evaluation. It was measured in the antero-posterior X-ray.

The results in our study were as follows

Normal (30-45 degrees)

$17(77 \%)$

Vertical (> 45 degrees)

$3(14 \%)$

Horizontal cup ( $<30$ degrees)
$2(9 \%)$ 


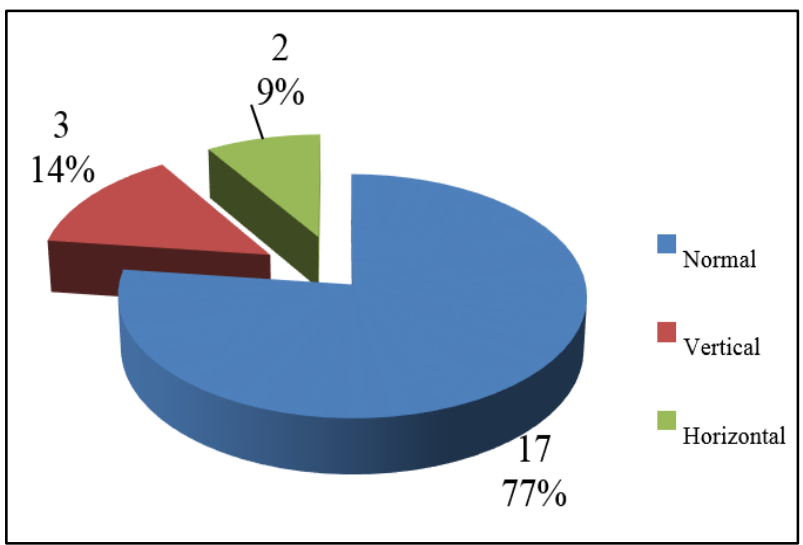

Fig. 4

\section{Femoral Stem Position}

The position of the femoral stem examined on the AP view $\mathrm{X}$-ray. In our study the results were as follows

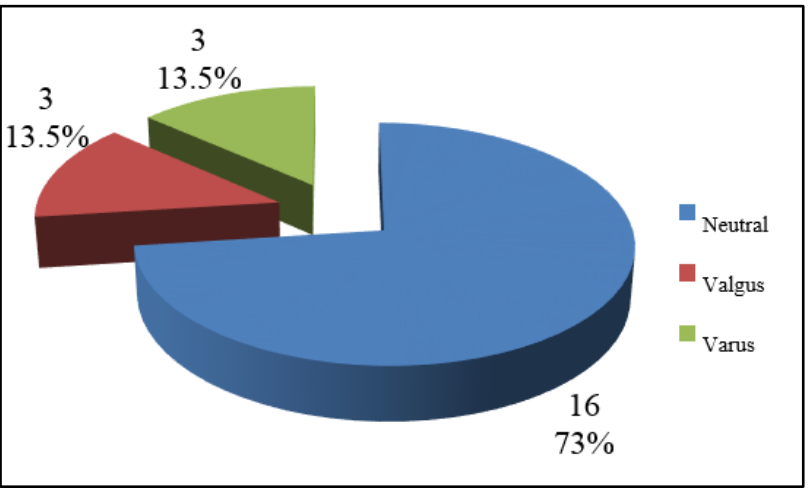

Fig. 5

\section{Vertical Subsidence}

Vertical subsidence was measured on the X-ray AP view. A decrease of $5 \mathrm{~mm}$ or more in the vertical position was considered to indicate subsidence.

There was no incidence of subsidence in our study.

\section{Acetabular Cup Migration}

There was no incidence of migration of acetabular component in our study.

\section{Heterotopic Ossification}

Heterotopic bone was graded according to Brooker et al. ${ }^{5}$ classification. In our series we found 1 hip (4.5\%) which developed type II heterotopic ossification.

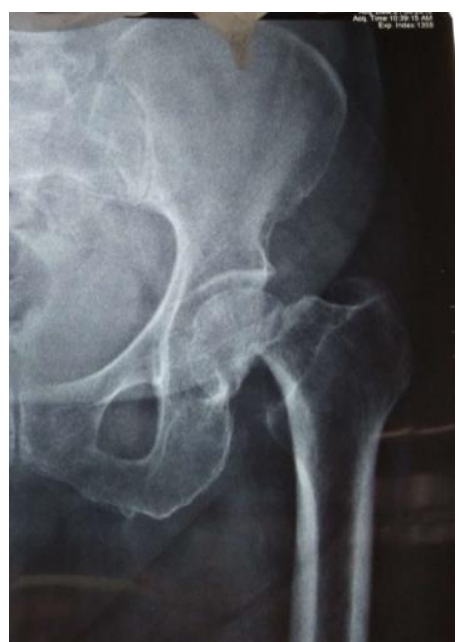

Fig. 6: Neck of femur fracture

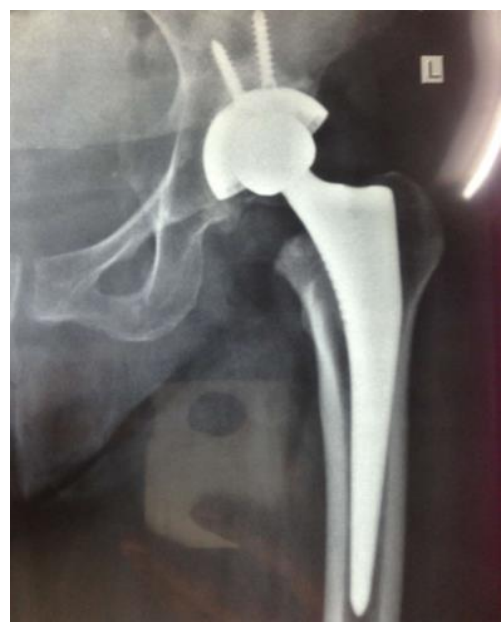

Fig. 7: Uncemented THA

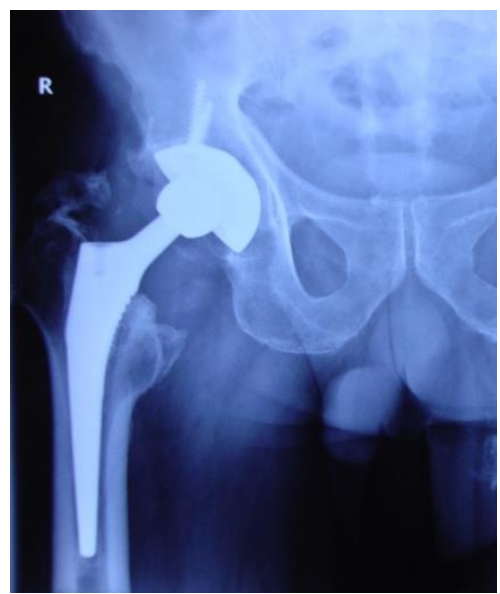

Fig. 8: Heterotopic ossification

Discussion

Discussion of the radiological outcome includes the following

1. Implant loosening.

2. Cup inclination.

3. Femoral stem position. 
4. Subsidence and migration

5. Dislocation

6. Heterotopic ossification

\section{Implant Loosening}

John C and W.H. Harris ${ }^{6}$ (JBJS 1999) presented a series of 188 Harris-Galante porous coated acetabular components that were followed for an average of 122 months. The hips were evaluated with Judet radiographs as well as anteroposterior and true lateral radiographs. $4 \%$ (8hips) had osteolytic lesions of the pelvis and less than $1 \%$ (1hip) had an osteolytic lesion that necessitated bone grafting.

Engh C.A. Jr et $\mathrm{al}^{7}$ (JBJS 1997) reported in his series, 174 hips were followed for a minimum of 10years. A total of 7 acetabular components, i.e., $4.02 \%$ of the 174 hips were radiographically loose. 4 patients of the 174 hips had symptomatic loosening of the acetabular cup, and the cup was revised eight, nine, ten and 12 years after index arthroplasty. The other 3 hips were not revised because they were not causing any symptoms. The average duration between the index operation and the diagnosis of loosening was 7.8 years.

Zicat and Engh ${ }^{8}$ (JBJS 1995) studied 51 cemented and 71 uncemented hips for evidence of osteolysis. The mean duration of follow up was 105 months. The rate of acetabular osteolysis in the patients who had a cup that had not been inserted with cement was not as high as that associated with cups that had been inserted with cement. The rate of acetabular osteolysis was $18 \%$ (13 of the 71 hips) in the uncemented hips with localized and expansile osteolysis pattern. In contrast, the rate of acetabular osteolysis in cemented hips was $37 \%$ (19 of 51 hips). The osteolysis was most frequently of the linear type. Although the pattern of osteolysis in cemented hips produced less bone loss than the localized and expansile pattern of the uncemented cups, the prevalence of loosening was high.

In the study by John C and W.H. Harris with mean follow up is 31.9 months there was no implant loosening. Conversely, long term review is essential to assess the exact mechanisms of polyethylene wear, defect in locking, separation of the linear and pelvic osteolysis.

\section{Acetabular Cup Inclination}

The normal acetabular cup inclination is $30^{\circ}$ to $45^{\circ}$. In this sequence 17 neutral, 3 vertical and 2 horizontal position were seen.

\section{Femoral Stem Position}

The ideal position of stem of femoral component is central. In this study we had 16 central, 3 each in valgus and varus position. Varus position of the stem may lead to complications such as anterior thigh pain and periprosthetic fractures. Till the most recent review the femoral stem position has not changed in any patients.

\section{Subsidence and Migration}

In this study there were no subsidence and migration.

\section{Dislocation}

There was no dislocation cases.

\section{Heterotopic Ossification}

It is seen on $\mathrm{X}$-rays only 3 weeks post operatively, following THA and well defined in 6 months. ${ }^{9-11}$ The incidence of heterotrophic ossification ranges from $5 \%$ to $90 \%$ in various literatures. ${ }^{12,13}$

In our sequence 1 patient with class II heterotrophic ossification seen. The bone marrow and debris escape when uncemented femoral implant is used however there is less chance for this when cemented implant is used.

The increased distribution of bone debris or marrow elements locally could lead to the stimulation (jbjs 73-A: 191-193, Feb 1991) In a study by William J. Maloney and William H. Harris, (1991 JBJS) the incidence of heterotopic ossification in an uncemented group and a hybrid group were compared. 65 uncemented and 70 hybrid (uncemented acetabular component and cemented femoral component) total hip replacements with minimum follow up of 1 year were reviewed. In the group who had uncemented hip replacement, there was a statistically significant increase in the incidence of heterotopic ossification. No relationship between the age of patient and formation of new bone was established. In our study we had 1 case of heterotopic ossification who underwent uncemented conversion THR.

In a study by Ravikumar et $\mathrm{al}^{14}$ (JBJS) they reviewed a total of 134 uncemented hips with average follow up of 83 months. Based on Brooker classification Heterotopic ossification was rated as Brooker Class I in 68 hips, Class II in 17 hips, Class III in 3 hips and Class IV in 2 hips, i.e., $50.7 \%$ in Class I, $12.7 \%$ in Class II, $2.2 \%$ in Class III and $1.5 \%$ in Class IV.

In our study Class II heterotopic ossification was noted in 1 hip, i.e., $4.5 \%$ incidence who underwent THA.

\section{Conclusion}

The results from this study shows that Total Hip Arthroplasty gave better results in displaced Intracapsular Neck of femur Fracture radiologically. Also there was no loosening of Acetabular component or migration of acetabular cup and cup position was normal in $77 \%$ cases. Femoral stem position was Neutral in $73 \%$ of cases with no vertical subsidence and no femoral component loosening. Conversely, long term review is essential to assess the exact mechanisms of polyethylene wear, defect in locking, separation of the liner and pelvic osteolysis.

\section{Conflict of Interest: None.}

\section{References}

1. Andrew, Whaley, and Daniel. Criteria for loosening of uncemented acetabular component. JBJS 83A 2001.

2. Campbell's Operative Orthopaedics' international edition: eleventh edition.

3. Engh's criteria for loosening of uncemented femoral component. Clin Orthop 1990-257.

4. Mont, MA, Maar, Dc. Krackow, K.A, Jacobs M. A. Jones total hip replacement without cement for non-inflammatory osteoarthritis in patients who are less than 45 yrs old. $J$ Bone $J$ Surg 1993;75A;740-51. 
5. Brooker AF, Bowermann RA, Railey LH. Ectopic ossification following THR, Incidence and classification. JBJS 1973;55A:1629-32.

6. William H. Harris, John. The Harris Galante porous coated acetabular component with screw fixation. J Bone J Surg 1999;81-A:66-73.

7. Engh C. AJR Culpepper, W.J H and Engh. CA long term results of use of anatomic medullary locking prosthesis in total hip arthroplasty. J Bone Joint Surg 1997;79-A177-84.

8. Zicat B, Engh CA and Gokeen E Patterns of osteolysis around the total hip components inserted with and without cement. JBJS 1995;77-A:432-9.

9. Delee Jesse, Ferrari, Antonio and Charnley. John ectopic bone formation following low friction arthroplasty of hip. Clin Orthop 1976;121:53-7.

10. Ritter MA and Gioe. The effect of indomethacin on periarticular ectopic ossification following THA. Clin Orthop 1982;167:113-7.

11. Hamblen D. Lectopic ossification in complications of THR. Edited by R.S.M ling London, Churchill Livingston 1984.

12. Chapman's orthopaedic surgery- $4^{\text {th }}$ edition.

13. Rosendahl S, Christofferson J.K and Norgaaid M. Para articular ossification following hip replacement. 70 arthroplasties ad modum moore using mc Farland approach. Acta Orthop Scand 1977;48:400-4.

14. Ravikumar J Kasetti A. Shetty and C. Rand Heterotropic ossification after uncemented hydroxy appatite coated THR. $J$ Arthroplasty 2001;16(8):1038-42.

How to cite this article: Jose RS. Study of radiological outcome of total hip arthroplasty in displaced neck of femur fracture. Indian J Orthop Surg 2019;5(2):123-7. 